\title{
Hepatitis C Update and Expanding the Role of Primary Care
}

\author{
Gina M. Simoncini, MD, MPH and David E. Koren, PharmD
}

Primary care physicians (PCPs) are increasing their role in the fight against the Hepatitis C Virus (HCV). Approximately 3.5 million Americans currently live with chronic HCV with rising incidence among young persons, especially those affected by the opioid epidemic. Online guidelines and drug interaction checkers streamline treatment and increase accessibility for both patients and providers. Although treatment with new Direct Acting Antiviral agents ensure cure rates that routinely exceed 95\%, as well as cause fewer adverse effects than previously available interferon-based regimens, some states still restrict access to HCV treatment, including by mandating which providers can prescribe and treat HCV. This special communication reviews HCV treatment resources, discusses data demonstrating similar cure rates between PCPs and specialists, and argues that capacity-building among PCPs will be necessary to control the HCV epidemic. (J Am Board Fam Med 2019;32:428-430.)

Keywords: Antiviral Agents, Hepatitis C, Primary Care Physicians, Sustained Virologic Response

According to the Centers for Disease Control and Prevention, there are over 3.5 million Americans living with hepatitis $\mathrm{C}$ virus $(\mathrm{HCV}) .{ }^{1}$ Persons born between 1945 and 1965 comprise the majority of Americans living with HCV; however, HCV incidence has been rising among young persons, especially those affected by the opioid epidemic. ${ }^{1,2}$ Treatment for HCV, now using direct-acting antivirals (DAAs), made staggering progress in the past 6 years with sustained virologic response rates that now routinely exceed $95 \%$. These new regimens are both simpler to administer and have fewer adverse effects than previously used interferon and ribavirin-based regimens. Therefore, we believe this is an opportune time for primary care physicians (PCPs) to become familiar with the DAAs. In addition, the first generic options for treatment

\footnotetext{
This article was externally peer reviewed.

Submitted 24 September 2018; revised 4 January 2019; accepted 8 January 2019.

From Lewis Katz School of Medicine at Temple University, Philadelphia, PA (GMS); Temple University Hospital, Philadelphia, PA (DEK).

Funding: none.

Conflict of interest: Gilead Sciences, Inc. (research funding GMS, DEK, advisory board - DEK) and ViiV Healthcare (advisory board - DEK).

Corresponding autbor: Gina M. Simoncini, MD, MPH, Lewis Katz School of Medicine at Temple University, Philadelphia, PA 19140 (E-mail: ginasimo@temple.edu).
}

have now been released, which will hopefully expand access to care.

Several DAA combination products are available in the United States. A general comparison of the four first-line recommended regimens used in treatment-naïve patients can be found in Table 1 . Individual DAA agents fall into 3 distinct classes: nonstructural (NS) protein inhibitors $3 / 4$ affecting viral protease, NS5b affecting RNA polymerase, and NS5a with an unknown mechanism of action. The combined American Association for the Study of Liver Diseases/Infectious Diseases Society of America maintain an online guideline for the management and treatment of hepatitis $\mathrm{C}$, found at www.hcvguidelines.org. ${ }^{3}$ These guidelines provide further prescribing information, including management of patients with cirrhosis or with comorbidities such as HIV or chronic kidney disease.

The most common drug-drug interactions involve these agents and $\beta$-hydroxy $\beta$-methylglutaryl-coenzyme A reductase inhibitors (statins), acid-suppressing medications, and antiepileptics. However, for clinicians managing potential and known interactions, the University of Liverpool comprehensive drug interaction database, found at www.hep-druginteractions.org, remains the most complete tool. ${ }^{4}$ In practice, side effect profiles of the DAA agents remain minimal, with adverse ef- 
Table 1. Comparison of Recommended First-Line Direct-Acting Antiviral Regimens Used for Treatment of Treatment-Naïe Hepatitis C Patients, as of 1/1/2018

\begin{tabular}{|c|c|c|c|c|}
\hline $\begin{array}{l}\text { Name of Direct-Acting } \\
\text { Antiviral Combination } \\
\text { Product }\end{array}$ & $\begin{array}{l}\text { Ledipasvir/Sofosbuvir } \\
\text { (Harvoni), } 90 \text { to } \\
400 \mathrm{mg}\end{array}$ & $\begin{array}{l}\text { Velpatasvir/Sofosbuvir } \\
\text { (Epclusa), } 100 \text { to } 400 \mathrm{mg}\end{array}$ & $\begin{array}{c}\text { Grazoprevir/ } \\
\text { Elbasvir (Zepatier), } \\
50 \text { to } 100 \mathrm{mg}\end{array}$ & $\begin{array}{l}\text { Glecaprevir/Pibrentasvir } \\
\text { (Mavyret), } 100 \text { to } 40 \mathrm{mg}\end{array}$ \\
\hline Drug classes & NS5a-NS5b & NS5a-NS5b & NS3/4-NS5a & NS3/4-NS5a \\
\hline Genotypes & $1,4,5,6$ & $1,2,3,4,5,6$ & 1 and 4 & $1,2,3,4,5,6$ \\
\hline $\begin{array}{l}\text { Dosage for } \\
\text { noncirrhotic patients }\end{array}$ & $\begin{array}{l}1 \text { tablet daily for } 12 \\
\text { weeks* }\end{array}$ & 1 tablet daily for 12 weeks & $\begin{array}{l}1 \text { tablet daily for } 12 \\
\text { weeks }^{\dagger}\end{array}$ & $\begin{array}{l}3 \text { tablets daily for } 8 \\
\text { weeks }\end{array}$ \\
\hline $\begin{array}{l}\text { Can be used in patients } \\
\text { with severe CKD } \\
(\mathrm{CrCl}<30 \mathrm{~mL} / \mathrm{min})\end{array}$ & No & No & Yes & Yes \\
\hline Cost estimate ${ }^{\ddagger}$ & $\$ 96,000$ & $\$ 75,000$ & $\$ 55,500$ & $\$ 27,000$ \\
\hline
\end{tabular}

${ }^{*}$ Genotype 1 patients who are non-black, HIV-uninfected, and whose HIV RNA level is $<6$ million IU/mL may be treated with 8 weeks of Ledipasvir/Sofosbuvir

${ }^{\dagger}$ For Genotype 1a patients without baseline NS5a resistance associated substitutions for elbasvir (positions 28, 30, 31, or 93), all Genotype $1 \mathrm{~b}$ patients, and all Genotype 4 patients.

${ }^{\ddagger}$ Estimated retail price of treatment based on information obtained at http://www.goodrx.com (accessed January 4, 2018).

fects such as headache, nausea, and fatigue as the most common symptoms throughout clinical trials.

Although these medications are safe and effective, some states still have restrictions about $\mathrm{HCV}$ treatment. Some states have fibrosis and/or sobriety restrictions that restrict treatment based on a patient's degree of liver damage or sobriety length. In addition, some states restrict the scope of practice of PCPs by requiring a specialist or a PCP in coordination with a specialist to treat patients living with HCV. A summary list of these restrictions by state can be found at stateofhepc.org. Despite these restrictions, there are studies that demonstrate that trained PCPs can not only treat HCV but also have similar outcomes as specialists. In 2004, Project Extension for Community Health care Outcomes (ECHO) began using case-based learning and videoconferencing with specialists to train PCPs to independently deliver $\mathrm{HCV}$ treatment in New Mexico. ${ }^{5}$ Before the training, none of the PCPs had treated HCV. During the published study period (2004 to 2008), Project ECHO enrolled 261 patients who were treated by PCPs and 146 patients who were treated by specialists using interferonbased therapy. Sustained virologic response rates were similar across both groups (PCPs, $45.8 \%$ and specialists, $49.7 \%[P=.57)])$. Most recently, A Phase IV Pilot Study to Assess Community-Based Treatment Efficacy in Chronic Hepatitis C Monoinfection and Coinfection With HIV in the District of Columbia (ASCEND) group demonstrated that PCPs, including nurse practitioners, were capable of providing effective DAA HCV therapy after a 3 -hour training. ${ }^{6}$ Cure rates (83\% to $89 \%$ ) among the 600 studied participants did not differ based on provider type, regardless if they were treated by PCPs, nurse practitioners, or specialists, although the cure rates were affected by patient loss to follow up. Both Project ECHO and the ASCEND study built capacity among PCPs to expand access to HCV treatment and demonstrated that high sustained virologic responses are both achievable and consistent among all clinician types.

Primary care providers seeking to treat hepatitis C should be aware that all insurance companies currently require prior authorization for payment on a DAA. Both virus-specific, such as HCV genotype, and comorbidity-specific labs, such as HIV and hepatitis B status, are required to be submitted with the authorization. Specific documentation of any adherence barriers, including mental health and sobriety, may need to be addressed by the prescriber. Some states also require prescribers to counsel patients on sobriety from drugs and alcohol. It is recommended that providers research their patients' commonly used insurance plans to both meet these requirements, as well as determine the preferred formulary agent on a patient's plan because there are high rates of insurance denials of HCV treatment. A study of national HCV DAA prescription trends demonstrated that $35 \%$ of patients were denied HCV treatment by insurance. Commercial insurance plans denied $52.4 \%$ of prescriptions submitted, Medicaid denied $34.5 \%$, and Medicare denied $14.7 \%$ of HCV DAA prior authoritizations. ${ }^{7}$ These denials from insurance do 
create an administrative burden for providers who treat $\mathrm{HCV}$, and as such, we recommend a multidisciplinary approach, including pharmacy representatives, to enhance the transparency of insurance coverage and assist with medication accession.

The National Viral Hepatitis Roundtable and the Center for Health Law and Policy Innovation of Harvard Law School published a report demonstrating 35 state Medicaid programs requiring a specialist to either consult or directly prescribe DAA therapy. ${ }^{8}$ These restrictions effectively limit access to $\mathrm{HCV}$ treatment. We agree with the American Academy of Family Physicians and the expert committee convened by the National Academy of Sciences that PCPs who have the desire and medical knowledge should be permitted to treat and prescribe DAAs for HCV. ${ }^{9,10}$ State-level advocacy to change Medicaid provider restrictions, while simultaneously training PCPs to build capacity to treat $\mathrm{HCV}$, will be the necessary next steps to control the HCV epidemic and reach patients in areas that often lack specialist care, especially in rural areas.

To see this article online, please go to: http://jabfm.org/content/ 32/3/428.full.

\section{References}

1. Centers for Disease Control and Prevention. Hepatitis $\mathrm{C}$ kills more americans than any other infectious disease. Available from: https://www.cdc.gov/media/ releases/2016/p0504-hepc-mortality.html. Published 2016. Accessed January 2, 2018.

2. Centers for Disease Control and Prevention. New hepatitis $\mathrm{C}$ infections nearly tripled over five years. Available from: https://www.cdc.gov/nchhstp/ newsroom/2017/Hepatitis-Surveillance-Press-
Release.html. Published 2017. Accessed January 2, 2018.

3. American Association for the Study of Liver Diseases, Infectious Diseases Society of America. Recommendations for testing, managing, and treating hepatitis $\mathrm{C}$. Available from: http://www.hcvguidelines.org. Published 2014. Accessed January 5, 2018.

4. University of Liverpool. Hep drug interactions. Available from: https://www.hep-druginteractions.org/ checker. Published 2019. Accessed January 8, 2018.

5. Arora S, Thornton K, Murata G, et al. Outcomes of treatment for hepatitis c infection by primary care providers. N Engl J Med. 2011;364:2199-220707.

6. Kattakuzhy S, Gross C, Emmanuel B, et al. Expansion of treatment for hepatitis $\mathrm{c}$ virus infection by task shifting to community-based nonspecialist providers: a nonrandomized clinical trial. Ann Intern Med 2017;167:311-8.

7. Gowda C, Lott S, Grigorian M, et al. absolute insurer denial of direct-acting antiviral therapy for hepatitis C: a national specialty pharmacy cohort study. Open Forum Infect Dis. 2018;5:ofy076.

8. National Viral Hepatitis RoundTable and Center for Health Law and Policy Innovation at Harvard Law School. Hepatitis C: state of medicaid access, provider restrictions. Available from: https://stateofhepc. org/wp-content/uploads/2017/10/PrescriberInfographic.pdf. Published 2017. Accessed January 2, 2018.

9. Sederstrom, J. Prescriber restrictions hurt hepatitis C patients, AAFP argues. Available from: https:// www.aafp.org/news/health-of-the-public/20160420 hepcaccess.html. Published 2016. Accessed February 7, 2018.

10. National Academy of Sciences. A national strategy for the elimination of hepatitis B and C. Available from: http://www.nationalacademies.org/hmd/ reports/2017/national-strategy-for-the-elimination-ofhepatitis-b-and-c.aspx. Published 2017. Accessed January $2,2018$. 